\title{
An Examination of the Flow Characteristics of Crude Oil: Evidence from Risk-Neutral Moments
}

\author{
Arjun Chatrath* Hong Miao ${ }^{\dagger} \quad$ Sanjay Ramchander ${ }^{\ddagger}$ \\ Tianyang Wang§
}

December 10, 2015

\begin{abstract}
This paper examines the information content of risk-neutral moments to explain crude oil futures returns. Implied volatility and higher moments are extracted from observed crude oil option prices using a model-free implied volatility framework and the Black-Scholes model. We find a tenuous and time-varying association between returns and implied volatility and its innovations. Specifically, changes in implied volatility are found to be meaningfully associated with crude returns only over the period spanning the recent financial crisis. The results lead us to conclude that crude oil prices are determined primarily in a flow demand/supply environment. Finally, we document that oil risk is priced into the cross-section of stock returns in the oil and transportation sectors.
\end{abstract}

Keywords: Risk-Neutral Moments, Crude Oil Futures, Returns, Volatility

JEL Code: G13, G14

\footnotetext{
*Portland's Pamplin School of Business, University of Portland, Portland, OR 97203, USA. Phone: 1-503-943-7465 Email: Chatrath@up.edu

${ }^{\dagger}$ Department of Finance and Real Estate, Colorado State University, Fort Collins, CO 80523, USA. Phone: 1-970-491-2356 Email: Hong.Miao@colostate.edu

${ }^{\ddagger}$ Department of Finance and Real Estate, Colorado State University, Fort Collins, CO 80523, USA. Phone: 1-970-491-6681 Email: Sanjay.Ramchander@colostate.edu

${ }^{\S}$ Corresponding Author. Department of Finance and Real Estate, Colorado State University, Fort Collins, CO 80523, USA. Phone: 1-970-491-2381 Email: Tianyang.Wang@colostate.edu
} 


\section{An Examination of the Flow Characteristics of Crude Oil: Evidence from Risk-Neutral Moments}

\section{Introduction}

The price of crude oil exhibits sharp spikes rising from shallow valleys that are widely believed to be disruptive to the global economy (e.g., Pindyck and Rotemberg 1984; Barsky and Kilian 2004; Kilian 2008a, 2008b; Hamilton 1996; and Kilian and Lewis 2011). In a recent and dramatic episode, the price of West Texas Intermediate (WTI) rose from about $\$ 25$ to over $\$ 140$ per barrel between January 2007 and July 2008, and subsequently crashed to just 20 percent of that value by December 2008 Most recently, from late 2014 into 2015, the crude oil price experienced a precipitous drop from its range of $\$ 90$ to $\$ 110$ between 2012 and early 2014 to below $\$ 50$ per barrel. Such spikes are often accompanied by demands for investigations for price-manipulation and/or calls for greater regulation, especially of the derivatives markets that allow investors to take large speculative positions in highly leveraged bets. Behind such appeals is the implicit belief that crude oil prices are impacted in a significant manner by factors other than the prevailing market demand and supply conditions.

However, there seems to be very little empirical evidence in support of this belief. A recent article in Forbes states that, "From an academic standpoint, this is simply the market's way of solving the demand and supply equation. Lower oil prices are a consequence of ... more supply than demand. It also means that oil producers with higher costs of production than the current price of oil will now be forced to shut down. This will drive down supply, eventually forcing the price to come up to a certain equilibrium. $\left.\right|^{2}$ In this context, some recent academic studies characterize the price of crude oil as pri-

\footnotetext{
${ }^{1}$ The behavior of sharp peaks/shallow valleys is observed for other global commodities such as wheat, cotton and copper (e.g., Deaton and Laroque 1992).

${ }^{2}$ How Will The 2014 Drop In Oil Prices Affect The World Economy And Geopolitics? Forbes (published on Jan. 6, 2015) Accessable at http://www.forbes.com/sites/quora/2015/01/06/how-will-the2014-drop-in-oil-prices-affect-the-world-economy-and-geopolitics/
} 
marily being determined in a flow-demand/supply environment. For instance, Kilian and Murphy (2014) investigate global crude oil market in the framework of a structural model. The authors provide evidence that fluctuations in the flow demand for oil, rather than speculative trading or supply shocks, were primarily responsible for the price surge between 2003 and mid-2008. Kilian and Vega (2011) find that daily regressions of crude oil and gasoline returns on the surprise components of several U.S. macroeconomic announcements produce insignificant coefficients and low $R^{2}$ values. The weak response of returns to economic surprises is interpreted by the authors as being consistent with each (and consequently both) of the following: (a) energy prices are predetermined with respect to domestic macroeconomic aggregates; and (b) crude oil and gasoline prices are determined by flow supply and flow demand. Chatrath et al. (2012) reframe Kilian and Vega's tests by conditioning the responses of crude oil returns to macroeconomic news on the level of inventories. They show that crude oil remains unresponsive to macroeconomic news even during times of extreme inventory build-up (or build-down). Elder et al. (2013) argue that the results reported by Kilian and Vega (2011) and others may be an artifact of a particular identifying restriction commonly found in lower frequency structural vector autoregressive (VAR) models. Using high frequency data they show that oil prices are in fact closely tied with new economic information in ways that appear to be consistent with economic theory.

The purpose of this paper is to examine the relationship between futures (and spot) crude oil returns to the commodity's implied volatility and related higher moments that are obtained from option prices. The analysis is partly motivated by recent research that document the importance of higher-moment risk in the pricing of financial assets, thus implicating market-wide volatility risk as a priced factor in the cross-section of stock returns (see for example, Ang et al. 2006; Adrian and Rosenberg 2008). Still other studies examine the explanatory power and information content of various volatility estimates, including historical volatility of underlying equity returns, the Black-Scholes 
(B-S) implied volatility, and more recently, model-free implied volatility. However, the question of how these different volatility estimates affect commodity price movements, which are known to exhibit return characteristics that are different from equity markets (such as mean reversion), is one that seems to have received scant attention in the literature. We believe that an examination of the relationship between crude oil prices and risk-neutral implied volatility represents an important contribution to the literature.

An additional contribution of our study is that it lends itself to further understanding the stock versus flow characterization of crude oil by proposing an alternative framework of tests. In particular, we propose a pure flow commodity is one where prices are impacted only by immediate net demand, and therefore impervious to speculative activity (e.g., Clower and Bushaw, 1954; Baumol, 1962) $!^{3}$ The analytical framework proposed in this study is consistent with recent studies such as Kilian and Vega (2011) and Chatrath, et al. (2012), who also deploy spot and futures return sensitivities in their assessment of the crude oil market. $4^{4}$ While the stock-flow analysis focuses attention on the existence and stability of a set of market-clearing prices in pure stock and flow models, it is worth noting that evaluating return response in the context of traditional asset pricing model and stockflow analyses may be mutually constitutive, as elements of both may prevail depending on economic circumstances. The current paper assesses whether crude prices respond to changes in market expectations that are embodied by implied moments obtained from option prices. The results from this study carry implications for policy debates on whether oil prices are impacted by factors other than the prevailing demand and supply conditions in the economy.

\footnotetext{
${ }^{3}$ Regulators and policy makers have different expressed views in this respect. On 20 May 2008, the chief economist at the Commodity Futures Trading Commission (CFTC) insisted at a Senate hearing that speculation was not causing the spike in the price of crude. Instead, he suggested that prices were driven "by powerful economic fundamental forces and the laws of supply and demand." Less than a fortnight later, after further pressure from Congress, the CFTC announced it would consider further oversight of energy futures trading ("Oil Traders Face New Regulation", Bloomberg Businessweek, June $9,2008)$. Also, see the public policy debate entailed in Masters (2008).

${ }^{4}$ Still other papers such as Baker (2012), Tang and Xiong (2010) and Hamilton and Wu (2013) take direct aim at explaining oil price spikes using some combination of rising spot prices, increased commodity derivatives trade, and changing risk premia.
} 
Our empirical study of the association between crude oil price-dynamics and implied higher moments spans the period 1996 to 2011. Two daily measures of implied volatility are extracted from futures options on crude oil: a model-free estimate that represents the implied volatility for at-the-money, constant-expiry options (henceforth model-free implied volatility); and the standard Black-Scholes model using at-the-money options (henceforth B-S implied volatility).

These measures are employed to answer three questions as they relate to the crude oil market: (i) Does the price of crude oil reflect expected volatility? In addressing this question, we re-examine the assertion in Kilian and Vega (2011), Chatrath et al. (2012) and Kilian and Murphy (2014) that crude oil is primarily a flow commodity. (ii) Is the price sensitivity of crude oil changing over time? It has been argued that commodity markets have experienced a large degree of "financialization" (via index fund investing) in the past decade that may have altered the structure of crude oil price risk premia over time. For instance, researchers note a sharp rise in the correlation among commodities and other asset classes after 2000, adding fuel to the argument that investors are increasingly treating commodities as investment assets (Singleton 2013; Irwin and Sanders, 2011; Tang and Xiong, 2010) ${ }^{5}$ If this is the case, then only more recently in our sample should we expect crude oil prices to more closely reflect market expectations on volatility. To examine this proposition we conduct a year-by-year examination of the empirical relationship between returns and implied volatility during the sample period. And (iii), is oil price risk priced into the returns of stocks in the oil and transportation sectors? At least part of the reason for the intense debate on whether or not crude oil is a pure flow commodity is due to the commodity's influential role in the economy and

\footnotetext{
${ }^{5}$ A recent J. P. Morgan's report ("Rise of Cross-Asset Correlations", May 2011) indicates that the correlation between U.S. commodities and equities which was -0.05 over $1990-1995$, rose to about 0.40 at by the end of 2009. The report also indicates a sharp rise in the correlation among other asset classes, and suggested a strong relationship between institutional trading and rising correlations. For instance, it is noted that the correlation between commodity groups themselves rose from around 0.10 between 1990 and 2000 (when commodity ETFs were practically nonexistent) to around 0.35 by 2010, by which time commodity ETF holdings were in the vicinity of $\$ 120$ billion.
} 
the potential impact it has on equity prices. Therefore, the third goal of this paper is to examine the influence of oil price and oil volatility risks on a cross-section of stock returns in the oil-sensitive sector of the economy.

The test results are summarized as follows.

1) On the pricing of implied volatility: The regression of crude oil returns, measured using either nearby futures or WTI spot prices, on implied volatility obtains an Adjusted- $R^{2}$ that is close to zero. Whereas, the overall regression produces a negative slope coefficient, it exhibits inconsistency (sign instability) when examined over smaller sub-samples. Similar results are obtained when returns are regressed on a measure of implied volatility that is purged of its relationship with realized volatility. The explanatory power of differenced-implied volatility is superior to that of level volatility, and this power improves further when the returns and differenced-implied volatility association is conditioned on risk-neutral skewness and kurtosis. However, additional analysis indicates that any meaningful association between return and even changes to implied volatility is absent for the majority of the investigated sample. Thus, we are unable to strongly support the notion that the crude oil market substantively and consistently "prices" expected volatility, a finding that is in line with a flow-oriented nature of the commodity.

2) On the temporal changes in the return-implied volatility relationship: We provide evidence of a closer association between crude oil returns and implied volatility since the beginning of the recent financial crisis. Returns are negatively related to implied volatility, especially the changes in implied volatility, between 2008 and 2011. Most strikingly, whereas the Adjusted- $R^{2}$ from the regression of returns to innovations in implied volatility is near-zero for each of the sampled years between 1996 and 2007, it rises to between 0.19 and 0.33 over the period 2008-2011. The substantial improvement in the relationship may be attributed to the growing financialization of the commodity during this period. However, it is also likely that the observed phenomenon of strengthening relationships between implied volatility and returns over this period are due to massive cross-currents in 
the marketplace, wherein prices (volatility) of all economically-sensitive assets fell (rose) together. Importantly, excluding this time period, the results are consistent with the view that crude oil prices are determined in a flow environment.

3) On the pricing of oil price and oil volatility risks in the cross-section of oil sensitive stock returns: We document that oil price risk is priced into the returns of stocks in the oil and transportation sectors. The results indicate that within the oil industry, stocks with high sensitivities to oil price risk tend to have high average returns, and stocks with high sensitivities to oil volatility risk generally have low average returns. In the transportation industry, stocks with high sensitivities to both oil price and oil volatility risks have low average returns. We provide an explanation for this finding.

The remainder of this paper is organized as follows: Section 2 discusses the background and hypothesis. Section 3 provides framework for estimating model-free implied volatility and risk neutral higher moments. Section 4 describes the data and the variables used in the study. Section 5 presents the results and Section 6 concludes the paper.

\section{Background}

Several studies examine the time-series relationship between aggregate volatility and expected stock returns, and in general find a negative price of risk for market volatility by using options written on the aggregate market index (see, for instance, Buraschi and Jackwerth 2001; Bakshi, Cao and Chen 2000; Coval and Shumway 2001). Ang et al. (2006) investigate the pricing of aggregate volatility risk in a cross-section of stock returns. Their study confirms a statistically significant negative price of risk for aggregate volatility, suggesting that risk-averse investors prefer stocks with high market volatility loadings to hedge against systematic risk and therefore requiring lower returns. In this paper, we extend the analysis to examine the influence of crude oil implied volatility on oil-related stock returns. 
In a related vein, a number of studies explore the predictive power of implied volatility obtained from options traded on financial assets. The consensus finding is that implied volatility outperforms other measures of volatility in predicting future volatility, even though it is found to be a biased forecasting metric (e.g. Poon and Granger 2003). In the commodity literature, Day and Lewis (1992) and Martens and Zein (2004) show implied volatility have explanatory power in predicting future volatility for crude oil. Kroner et al. (1995) provide similar evidence for other commodities such as cocoa, corn and gold. Szakmary et al. (2003) show that it is a biased forecasting mechanism for a range of commodities including crude oil. Khalifa et al. (2011) study the volatility forecasting in metal futures market. More recently, Chatrath et al. (2015) suggest that model-free implied volatility have good predictability of future crude oil volatility, and the third and fourth risk neutral moments (i.e., risk neutral skewness and kurtosis) also contain useful information about future realized volatility.

In this study we posit that the association (or lack thereof) between current crude returns and implied volatility represents a useful test of the stock-versus-flow orientation of the commodity. In a pure flow demand/supply environment, prices will be relatively impervious to expectations relating to future demand and supply conditions (e.g., Clower and Bushaw, 1954; Baumol, 1962). With growing evidence that implied volatility provides a fair representation of expected volatility (e.g.,Chatrath et al. 2015), if current price dynamics are found to be unrelated to implied volatility, the results would lend support to those who argue that crude oil is primarily a flow-demand, flow-supply commodity. On the other hand, a stock-flow characterization of the commodity would be warranted if current prices are found to be significantly related to expected volatility (Adrangi et al. 2014).

Given prior research on implied volatility that shows it to be strongly associated with future (realized) volatility (e.g. Poon and Granger 2003; Chatrath et al. 2015), implied volatility appears to be an appealing metric for testing the stock versus flow characteriza- 
tion of crude oil. For instance, a significant slope coefficient from the regression of crude oil return on implied volatility along with a substantial regression $R^{2}$ would suggest that the crude oil market prices expected volatility, and this would imply that crude oil is a not a flow commodity. On the other hand, an absence of relationship would suggest that we cannot reject the hypothesis that crude oil is a flow commodity. Such an analytical framework is wholly consistent with that taken in Kilian and Vega (2011). We follow the approaches in Jiang and Tian (2005) and Bakshi et al. (2003) to construct modelfree higher moments that allow us to examine the relationship between various implied volatility estimates and the expected returns of crude oil futures.

It is to be noted that if implied volatility (also) reflects current market conditions, its deployment as an independent variable in the regression of crude oil returns may result in a Type I error. Therefore, a robust deployment of implied volatility or its surrogate would require that it be relatively unrelated to the current price dynamics and yet represents a good metric for future volatility. Despite this concern, the stock/flowdistinction technique described above has the advantage in that it is intuitive, and may be deployed for any commodity for which option trading is available. Notably, from the continuing dispute over the origins of volatility (for commodity prices in general), it is clear that attempts at the characterization of a commodity as either flow or stock-flow should be considered as much more than an academic exercise ${ }^{6}$ For instance, the price of a mostly-flow commodity will be relatively unresponsive to trading activity (on options and futures contracts, for instance), and hence also to regulation that attempts to limit it.

\footnotetext{
${ }^{6}$ Some recent literature take a more direct approach in evaluating the claim that speculative drivers underlie spikes in crude oil pries by basing their analysis on some combination of rising spot prices, increased commodity derivatives trade, and changing risk premia (see Gorton et al., 2013; Hamilton and Wu, 2013; Buyuksahin et al., 2011; Baker, 2012; and Hong and Yogo, 2012).
} 


\section{The Risk Neutral Higher Moments}

Britten-Jones and Neuberger (2000) derive the model-free implied volatility under the assumptions that the underlying asset does not pay dividends and the risk-free rate is zero and follows a diffusion process. The model-free implied variance is defined as:

$$
E_{0}^{F}\left[\int_{0}^{T}\left(\frac{d F_{t}}{F_{t}}\right)^{2}\right]=2 \int_{0}^{\infty} \frac{C^{F}(T, K)-\max \left(0, F_{0}-K\right)}{K^{2}} d K,
$$

where $E^{F}$ refers to expectation under the forward probability measure, $C^{F}(T, K)$ is the forward price of a call option with maturity $T$ and strike $K$, and $F_{0}$ is the forward price of the underlying asset at time $t$.

In a similar spirit, Bakshi et al. (2003) present an approach to extract volatility, skewness, and kurtosis of the risk-neutral return distribution from a set of out-of-themoney options. The risk neutral volatility $\left(\sigma^{M F}\right)$, skewness $(S K E W)$, and Kurtosis ( $K U R T$ ) extracted at time $t$ with horizon $\tau$ can be expressed in terms of the fair values of the volatility contract, the cubic contract, and the quadratic contracts. The three contracts have the payoffs:

$$
H(S)= \begin{cases}R_{t, \tau}^{2} & \text { volatility contract } \\ R_{t, \tau}^{3} & \text { cubic contract } \\ R_{t, \tau}^{4} & \text { quadratic contract. }\end{cases}
$$

where, $R_{t, \tau}=\ln \left[S_{t+\tau}\right]-\ln \left[S_{t}\right]$ is the $\tau$-period return. The fair values of the three contracts are defined as

$$
\begin{aligned}
V_{t, \tau} & =E_{t}^{Q}\left[e^{-r \tau} R_{t, \tau}^{2}\right], \\
W_{t, \tau} & =E_{t}^{Q}\left[e^{-r \tau} R_{t, \tau}^{3}\right], \\
X_{t, \tau} & =E_{t}^{Q}\left[e^{-r \tau} R_{t, \tau}^{4}\right] .
\end{aligned}
$$


The four moments are expressed as:

$$
\begin{aligned}
\mu_{t, \tau}=E_{t}^{Q} \ln \left[\frac{S_{t+\tau}}{S_{t}}\right]=e^{r \tau}-1-\frac{e^{r \tau}}{2} V_{t, \tau}-\frac{e^{r \tau}}{6} W_{t, \tau}-\frac{e^{r \tau}}{24} X_{t, \tau} . \\
\sigma_{t, \tau}^{M F}= \\
S K E W_{t, \tau}=\frac{\sqrt{E_{t}^{Q}\left[R_{t, \tau}^{2}\right]-\mu_{t, \tau}^{2}}=\sqrt{e^{r \tau} V_{t, \tau}-\mu_{t, \tau}^{2}}}{\left\{E_{t}^{Q}\left[\left(R_{t, \tau}-E_{t}^{Q}\left[e^{-r \tau} R_{t, \tau}\right]\right)^{3}\right]\right.} \\
=\frac{e^{r \tau} W_{t, \tau}-3 \mu_{t, \tau} e^{r \tau} V_{t, \tau}+2 e_{t, \tau}^{3}}{\left.\left.\left[e^{r \tau} V_{t, \tau}-\mu_{t, \tau}^{2}\right]^{\frac{3}{2}}\right]\right\}^{2}} \\
K U R T_{t, \tau}=\frac{E_{t}^{Q}\left[\left(R_{t, \tau}-E_{t}^{Q}\left[e^{-r \tau} R_{t, \tau}\right]\right)^{4}\right]}{\left\{E_{t}^{Q}\left[\left(R_{t, \tau}-E_{t}^{Q}\left[e^{-r \tau} R_{t, \tau}\right]\right)^{2}\right]\right\}^{2}} \\
=\frac{e^{r \tau} X_{t, \tau}-4 \mu_{t, \tau} e^{r \tau} W_{t, \tau}+6 e^{r \tau} \mu_{t, \tau} 2 V_{t, \tau}-3 \mu_{t, \tau}^{4}}{\left[e^{r \tau} V_{t, \tau}-\mu_{t, \tau}^{2}\right]^{2}} .
\end{aligned}
$$

The contract's fair values are determined by spanning their payoffs by a portfolio of call and put options, as well as the underlying asset and a risk-free bond. It follows that $V(t, \tau), W(t, \tau)$, and $X(t, \tau)$ can be determined by a linear combination of out-the-money 
calls and puts, i.e.:

$$
\begin{aligned}
& V_{t, \tau}=\int_{S_{t}}^{\infty} \frac{2\left(1-\ln \left[\frac{K}{S_{t}}\right]\right)}{K^{2}} C_{t, \tau}(K) d K \\
& +\int_{0}^{S_{t}} \frac{2\left(1+\ln \left[\frac{K}{S_{t}}\right]\right)}{K^{2}} P_{t, \tau}(K) d K, \\
& W_{t, \tau}=\int_{S_{t}}^{\infty} \frac{6 \ln \left[\frac{K}{S_{t}}\right]-3\left(\ln \left[\frac{K}{S_{t}}\right]\right)^{2}}{K^{2}} C_{t, \tau}(K) d K \\
& -\int_{0}^{S_{t}} \frac{6 \ln \left[\frac{K}{S_{t}}\right]+3\left(\ln \left[\frac{K}{S_{t}}\right]\right)^{2}}{K^{2}} P_{t, \tau}(K) d K \\
& X_{t, \tau}=\int_{S_{t}}^{\infty} \frac{12\left(\ln \left[\frac{K}{S_{t}}\right]\right)^{2}-4\left(\ln \left[\frac{K}{S_{t}}\right]\right)^{3}}{K^{2}} C_{t, \tau}(K) d K \\
& +\int_{S_{t}}^{\infty} \frac{12\left(\ln \left[\frac{K}{S_{t}}\right]\right)^{2}+4\left(\ln \left[\frac{K}{S_{t}}\right]\right)^{3}}{K^{2}} P_{t, \tau}(K) d K .
\end{aligned}
$$

While the model-free estimates of implied volatility and higher moments are theoretically appealing, and it is straightforward to evaluate the quantity $V_{t, \tau}, W_{t, \tau}$, and $X_{t, \tau}$, in practice, it is computationally challenging to estimate. Since the right hand of equation 1 involves an integral of option prices over an infinite range of strike prices, it is impossible to be calculated accurately. Jiang and Tian (2005) present an approach to approximate the necessary value. Suppose the interval of available strike prices is defined as $\left[K_{\min }, K_{\max }\right]$, then the right hand side of Equation 1 can be approximated by the following integral:

$$
2 \int_{K_{\min }}^{K_{\max }} \frac{C^{F}(T, K)-\max \left(0, F_{0}-K\right)}{K^{2}} d K
$$

Jiang and Tian (2005) discuss a relatively tight theoretical model-dependent upper bound and a less tight model-free upper bound for truncation errors when a finite range of strikes is used.

In practice, a greater computational challenge of the model-free implied volatility is 
that we do not observe a range of continuous strike prices of calls. Thus, Jiang and Tian (2005) approximate the integral using the trapezoidal rule. That is:

$$
2 \int_{K_{\min }}^{K_{\max }} \frac{C^{F}(T, K)-\max \left(0, F_{0}-K\right)}{K^{2}} d K \approx \sum_{i=1}^{m}\left[g\left(T, K_{i}\right)+g\left(T, K_{i-1}\right)\right] \Delta K,
$$

where $\Delta K=\left(K_{\max }-K_{\min }\right) / m, K_{i}=K_{\min }+i \Delta K$ for $0 \leq i \leq m$, and $g\left(T, K_{i}\right)=$ $\left[C^{F}\left(T, K_{i}\right)-\max \left(0, F_{0}-K_{i}\right)\right] / K_{i}^{2}$.

In summary, since there is no continuous series of strike prices and the range of strike prices are limited, approximation and numerical integration techniques are needed. This study uses an empirical approach similar to Jiang and Tian (2005) and Bakshi et al. (2003) to extract risk-neutral higher moments.7]

\section{Data Characteristics and Variable Computation}

This paper uses several types of data. The data period of the study span January 1996 through December 2011. We also hold out a sample, most recent three years from 2009 to 2011, for additional analysis due to the significant impact of the recent financial crisis on equity and commodity markets during this period. The closing prices of West Texas Intermediate (WTI) light sweet crude oil futures (ticker: CL) and options of oil futures (ticker: LO) are obtained from Chicago Mercantile Exchange (CME). Daily crude oil futures time series are constructed from near-term contracts switching to the next-term contracts when the near-term contracts are less than 10 days to expiration. To calculate the daily realized volatility of crude oil futures, we use the intra-day five minute frequency futures data from Tickdata. The risk-neutral higher moments and the B-S implied volatility are extracted from the crude oil options contracts. The risk-free rates used to extract volatility measures are obtained from the Treasury constant maturity curves provided by the Board of Governors of the Federal Reserve System. The stock market excess returns are obtained from

\footnotetext{
${ }^{7}$ We refer the interested reader to Jiang and Tian (2005) for more details.
} 
Kenneth French's web site (http://mba.tuck.dartmouth.edu/pages/faculty/ken.french/), and the daily stock returns for oil and transportation companies and value-weighted market index returns are obtained from the Center for Research in Security Prices (CRSP).

The futures contracts are traded through open outcry and the Globex electronic platform. Trading in the current delivery month ceases on the third business day prior to the twenty-fifth calendar day of the month. Options on light sweet crude oil futures are traded through the same platforms. Options are listed nine years forward with consecutive months contracts for the current year and next five years. Trading of options ends three business days before the termination of trading in the underlying futures contracts.

For the purposes of comparison we also consider other volatility measures in this study: historical volatility, realized volatility, lagged realized volatility, and implied volatility derived from the B-S model using at-the-money options. The monthly historical volatility refers to the standard deviation of daily returns in the previous calendar month. This study uses two realized volatility estimates: realized volatility using daily data and realized volatility using intra-day five minute interval data. The realized volatility of the previous calendar month is calculated using daily returns as follows:

$$
R V_{t}^{D}=\sqrt{12}\left(\sum_{i=1}^{n} r_{t-i}^{2}\right)^{1 / 2} .
$$

The daily lagged realized volatility is calculated using the five-minute interval returns during the previous trading day as:

$$
R V_{t}^{H}=\sqrt{252}\left(\sum_{i=1}^{n} r_{t-1, i}^{2}\right)^{1 / 2} .
$$

B-S option implied volatility is extracted from the previously constructed smoothed volatility surface by using cubic spline, fixing the maturity to 30 days, and setting the moneyness to at-the-money (strike/Futures=1). 
Table 1 reports summary statistics of the variables used in the study. Panel A and B shows summary statistics of the crude oil returns $R^{C L}$ and various daily volatility measures: the model-free implied volatility $\left(\sigma^{M F}\right)$, the B-S implied volatility $\left(\sigma^{B L}\right)$, the historical realized volatility $\left(\sigma^{H R E}\right)$, the historical volatility $\left(\sigma^{H}\right)$, the forward realized volatility $\left(\sigma^{R E}\right)$, and the lagged realized volatility $\left(\sigma^{L R E}\right)$ for the overall sample period (January 1996 to December 2011) and for the period January 2009 to December 2011, respectively. Panels $\mathrm{C}$ and $\mathrm{D}$ document the corresponding summary statistics of the same set of volatility measures and crude oil futures returns for monthly non-overlapping samples for the two periods. Following Jiang and Tian (2005), the monthly non-overlapping sample is constructed on the last Wednesday of each month. The monthly return is the return between the last Wednesday of each month and the last Wednesday of the previous month.

As shown in Table 1, daily crude oil returns $R^{C L}$ are close to zero and monthly crude oil returns $R^{C L}$ are close to $1.1 \%$ for the full sample, and a little bit higher for the most recent subperiod (2009-2011). Additionally, consistent with summary statistics from the general equity market in Jiang and Tian (2005), the mean of the model-free implied volatility $\left(\sigma^{M F}\right)$ is always the highest volatility estimate followed by the B-S implied volatility $\left(\sigma^{B L}\right)$, which is in turn higher than historical volatility $\left(\sigma^{H}\right)$. The lagged realized volatility $\left(\sigma^{L R E}\right)$ is found to have the lowest relative mean among the different measures. This pattern is evident across Panels A through D. The data characteristics suggest that both the model-free implied volatility $\left(\sigma^{M F}\right)$ and the B-S implied volatility $\left(\sigma^{B L}\right)$ are upward biased forecasts of realized volatility, with a slightly lower bias for the latter due to Jensen's inequality under stochastic volatility. The lagged realized volatility $\left(\sigma^{L R E}\right)$ is always the lowest since it is calculated using intra-day observations during the pit trading hours only. The skewness and kurtosis statistics reveal that the data is right skewed with positive kurtosis, which suggests that log volatility may be better modeled with normal distribution. 


\section{$5 \quad$ Empirical Results}

\subsection{Risk-Neutral Volatility and Returns}

Table 2 provides preliminary insights into the relationship between crude oil futures returns and implied volatility by return quintile. If such a depiction were to support the positive (negative) pricing of implied volatility, we should see the lowest (highest) returns associated with the highest (lowest) volatility (see, for example, Baker and Routledge, 2012; and Gorton et al., 2013). We do not see this in either the median or mean of the implied volatility variables. Instead, a fairly symmetrical U-shape in the two implied volatility measures is observed across the return quintiles. These results, which are consistent with Kogan et al. (2009), indicate that near-to-maturity futures returns are not linearly related to expected volatility. The absence of asymmetry suggests only a weak relationship between returns and volatility. Similar patterns are observed when using spot WTI returns in lieu of nearby futures returns (results not reported).

Asset returns are likely to be susceptible to various sources of uncertainty including uncertainty about returns as captured by return variance as well as uncertainty about the return variance itself. Therefore, a more formal investigation into the returns-volatility relationship is conducted by running the following regressions:

$$
\begin{aligned}
& r_{t, t+\tau}=\alpha+\beta^{i} \sigma_{t}^{i}+\varepsilon_{t}, \quad \text { for } i=M F, B L, \\
& r_{t, t+\tau}=\alpha+\beta^{i} \Delta \sigma_{t}^{i}+\varepsilon_{t}, \text { for } i=M F, B L, \\
& r_{t, t+\tau}=\alpha+\beta^{i} U_{t}^{i}+\varepsilon_{t}, \text { for } i=M F, B L, \\
& r_{t, t+\tau}=\alpha+\beta^{i} U_{t}^{\Delta i}+\varepsilon_{t}, \text { for } i=M F, B L,
\end{aligned}
$$

where $r_{t, t+\tau}$ refers to daily or 30-calendar day forward returns. The variables $U_{t}^{i}$ and $U_{t}^{\Delta i}$ 
are the residuals of the following regressions:

$$
\begin{gathered}
\sigma_{t}^{i}=\alpha+\beta^{i} \sigma_{t}^{L R E}+U_{t}^{i}, \text { for } i=M F, B L, \\
\Delta \sigma_{t}^{i}=\alpha+\beta^{i} \Delta \sigma_{t}^{L R E}+U_{t}^{\Delta i}, \text { for } i=M F, B L .
\end{gathered}
$$

The regressions of returns on innovations in implied volatility is arguably better suited to address the question of whether prices respond to changes in expectations about future variability since innovations in implied volatility is commonly considered to be a simple measure of information arrival in the options market.

Table 3 presents the estimated coefficients and corresponding statistics for these regressions using futures returns. Estimations using spot returns obtain very similar results and are not reported. Various return measurements including one-day forward returns $\left(r_{t+1}\right)$, day-by-day overlapping monthly forward returns $\left(r_{t+30}\right)$ and monthly non-overlapping returns $\left(r_{t+30}\right.$ sampled once every month) are alternately regressed on monthly implied volatility (changes). The results in Panel A relate to the regression of futures returns on levels of implied volatility. Only the daily return regressions produce statistically significant (negative) slope estimates. Notably, the Adjusted- $R^{2}$ is close to zero for all estimations. The results in Panel B are for the regressions of returns on changes in volatility. Once again, only the daily regressions obtain any level of statistical significance in the slope coefficient, and the Adjusted- $R^{2}$ remains close to zero. While not reported here, the results are even weaker when deploying the surrogate implied volatility estimate. To summarize, the results in Table 3 suggest only a weak correspondence between returns and implied volatility or innovations in implied volatility. The limited role for implied volatility in explaining crude oil returns adds to the mixed nature of evidence, relating to the risk-return trade-off, reported in the stock market (see Campbell and Hentschel, 1992; and Ghysels et al., 2005).

In the next step of the analysis we test whether the response of futures returns to 
implied volatility is contingent on implied higher moments (again estimates using spot prices are found to be qualitatively similar, and therefore not reported). The regression of daily returns is run on implied volatility and its innovations over samples representing low and high risk-neutral skewness and kurtosis. It is reasonable to anticipate, for instance, that the expectation of downward bias in the month-ahead will have a more negative impact on returns when the skewness is negative. Table 4 reports the results from the battery of regressions using implied volatility levels. Table 5 reports corresponding results on the sensitivity of returns to changes in implied volatility.

The first row of Table 4 reports result for Equation 12 with $\tau=30$, using daily data for the full sample, and represents the benchmark for the remaining results. Consistent with results that were reported earlier, the coefficient is weakly negative and the Adjusted- $R^{2}$ is close to zero. The second and third set of results are from the re-estimation of Equation 12 on data sorted by risk-neutral skewness and kurtosis, respectively. There is some indication of a slightly stronger (more negative) return-implied volatility relationship over days with positive risk-neutral skewness and higher-than-average risk-neutral kurtosis. However, the Adjusted- $R^{2} s$ remain close to zero across these alternate estimations. The final set of results relates to estimations for data sorted by the interaction between riskneutral skewness and kurtosis. The sub-sample with positive risk-neutral skewness and higher-than-average kurtosis obtains the only significant coefficient, marginally higher than the benchmark results obtained from the full sample. The overall explanatory power of each of the sub-samples sorted on skewness/kurtosis are near-zero. To summarize, the results reported in Table 4 suggest that the marked absence of association between crude oil returns and implied volatility cannot be explained by the 30-day ahead expectations on return bias and diffusion.

The relationship between one-day ahead returns and differenced implied volatility sorted on risk-neutral skewness and kurtosis is reported in Table 5. The first set of results suggest that the return - differenced implied volatility relationship is slightly stronger 
(more negative) than the return - implied volatility relationship evidenced in Table 4. The Adjusted- $R^{2}$ is also higher using differenced implied volatility, at 0.035 and 0.043 corresponding to the model-free and B-S measures, respectively. Further, both skewness and kurtosis appear to be useful controls in explaining the returns-implied volatility relationship. Most notably, days with negative (positive) implied skewness (kurtosis) are associated with a more negative association between returns and changes in implied volatility. The Adjusted- $R^{2}$ for the data sorted jointly for negative skewness and positive kurtosis is 0.22 , representing a marked improvement over the benchmark. Overall, the controls for implied skewness and kurtosis are found to improve the explanatory power of the innovations in implied volatility vis-a-vis crude oil returns.

The combined results in Tables 4 through 5 point to an inconsistent relationship between crude returns and implied volatility. The regression of returns on implied volatility or implied volatility changes yield weak Adjusted- $R^{2}$. Whereas, we find a stronger explanatory power in the differenced implied volatility, the enhancement is only achieved via explicit controls for implied skewness and kurtosis. At best, our results are indicative of only a tenuous relationship between crude oil returns and expected volatility. In our view, these results fall short in our ability to conclude that crude oil prices adequately capture variance risk premiums. A further assessment of the consistency (or lack thereof) in the association between returns and implied volatility innovations is achieved by regressions on small sub-samples of the data.

\subsection{Temporal Patterns in the Return/Implied Volatility Rela- tionship}

Our second analysis relates to the possibility that the growth in the interest in crude oil trading/investing (via exchange traded funds (ETF)s, for instance) has influenced the nature of the commodity. Specifically, we conduct this examination by estimating the relationship between returns and changes in implied volatility on a yearly basis. We 
estimate equation 12 and 13 for each year in the sample ${ }^{8}$ In both the models, $r_{t, t+\tau}$ is alternately measured using spot and nearby futures prices, and implied volatility is alternately introduced in its level and first difference. The results using spot prices are very similar to those obtained from the futures market; therefore, we report only the futures returns. Table 6 reports the results of the annual regressions of futures returns on implied volatility. The results across the two volatility measures are similar. The regression produces coefficient values that are neither consistent nor strong. While the majority of the samples (years) yield negative coefficients, the Adjusted- $R^{2}$ is very small. Interestingly, the years spanning the financial crisis (and beyond) yield slightly higher Adjusted- $R^{2} s$, ranging from 0.04 in 2009 to 0.14 in 2011.

Table 7 reports the results from using implied volatility changes. The patterns in the coefficients and Adjusted- $R^{2}$ are quite noteworthy in this case. Most striking are the results from regressions between 2008 and 2011 across both volatility measures. For these years, we observe consistently negative coefficients and Adjusted- $R^{2} s$ that rise (from nearzero in 2007 and before) to 0.19 in 2008 (B-S regression), 0.30 in 2009, 0.36 in 2010, and 0.34 in 2011. The substantial improvement in explanatory power suggests an increased financialization of the crude oil market. However, it is also possible that the strengthening in the relationship between implied volatility innovations and returns over the most recent period is due to the presence of massive cross-currents in the marketplace, wherein prices (volatility) of all assets fell (rise) together. In support of this line of reasoning we document a very weak/inconsistent association between returns and implied volatility innovations for periods falling outside the financial crises, periods that witnessed very large ETF-related inflows into commodity markets.

The weak associations noted (in Tables 6 and 7) between returns and implied volatility(innovations) between 1996 and 2008 are consistent with the characterization of floworientation of the commodity made by Chatrath et al. (2012), among others. Specifically,

\footnotetext{
${ }^{8}$ We also estimate the same set of regressions using surrogate implied volatility measures with the models 14 and 15 . The results are qualitatively very similar.
} 
these authors indicate that the sharp run up in oil prices between 2003 and 2008 was flow-demand/supply driven, a period during which we note a marked absence of a relationship between returns and implied volatility (innovations). In contrast, for the period after 2008, we do find an increase in the (negative) association between the variables. However, given the confounding influence of the financial crisis on all markets during our sample period it is somewhat difficult to conclude with certainty that the crude oil market can be recharacterized as an increasingly stock-flow oriented commodity. The time-varying association and the substantial improvement in the relationship between implied volatility and returns over the 2008-2011 period may also suggest that the crude oil price volatility is an additional countercyclical proxy for investment opportunities that may be present in the economy (see, Guo, Wang and Yang 2013).

\subsection{Oil Price Risk and Oil Volatility Risk}

In this section, we examine the pricing of oil price risk and oil volatility risk in a crosssection of stock returns sensitive. While oil price risk and oil volatility risk may not be broad risk factors for the entire stock market, research documents the impacts of crude oil prices on stock price movements for oil-sensitive companies. For instance, Gogineni (2010) finds a strong connection between oil related company stock returns and crude oil prices and Chatrath et al. (2014) document an association between the S\&P 500 returns and crude oil higher moments. This is futher substantiated by Chiang et al. (2015) who employ information from both equity and derivatives markets to show that even the average non-oil portfolio returns are sensitive to oil risk factors.

We hypothesize that oil price risk and oil volatility risk are important factors for companies whose operations heavily depend on the price of crude oil. For the purpose of the analysis we consider all stocks in the Petroleum and Natural Gas (Oil) industry (industry code 30) and the Transportation industry (industry code 40) in the Fama- 
French 48 industry portfolios $9^{9}$ Since the industry definitions are based on the four digital SIC codes of Compustat, we first define the industries in Compustat before using CRSP to obtain daily returns.

Ang et al. (2006) find that stocks with high sensitivities to innovations in aggregate volatility have low average expected returns. Our goal is to examine whether oil related stocks with different sensitivities to crude oil returns and crude oil volatility innovations have different average returns. To investigate the sensitivities of stocks to crude oil returns (crude oil price risk), we examine a simple two-factor model as follows:

$$
E R_{t}^{i}=\alpha+\beta_{i}^{M K T} E R_{t}^{M K T}+\beta_{i}^{C L} R_{t}^{C L}+\varepsilon_{t}^{i}
$$

where $E R_{t}^{i}$ is the daily excess return of stock $i$ at time $t, E R_{t}^{M K T}$ is the daily market excess return, $R_{t}^{C L}$ is the daily returns of crude oil futures at time $t$, and $\beta_{i}^{M K T}$, and $\beta_{i}^{C L}$ are the loadings on market risk factor and crude oil price risk.

To investigate the sensitivities of stocks to crude oil volatility proxied by $\sigma_{t}^{M F}$ (or $\left.\sigma_{t}^{B L}\right)^{10}$ we follow Ang et al. (2006) in setting up a two factor model:

$$
\begin{aligned}
& E R_{t}^{i}=\alpha+\beta_{i}^{M K T} E R_{t}^{M K T}+\beta_{i}^{M F} \Delta \sigma_{t}^{M F}+\varepsilon_{t}^{i}, \\
& E R_{t}^{i}=\alpha+\beta_{i}^{M K T} E R_{t}^{M K T}+\beta_{i}^{B L} \Delta \sigma_{t}^{B L}+\varepsilon_{t}^{i},
\end{aligned}
$$

where $\Delta \sigma_{t}^{M F}$, and $\Delta \sigma_{t}^{M F}$ are our proxies of innovation for the crude oil volatility factor, and $\beta_{i}^{M F}$, and $\beta_{i}^{B L}$ are the loadings on crude oil volatility risk proxied by $\sigma_{t}^{M F}$, and $\sigma_{t}^{B L}$, respectively.

We run monthly regressions $18-20$ for all stocks that contain more than 17 daily observations in the oil and transportation industry separately. We sort firms on $R_{t}^{C L}$, $\sigma_{t}^{M F}$, and $\sigma_{t}^{B L}$ loadings and absolute loadings, respectively, into quintiles from the lowest

\footnotetext{
${ }^{9}$ For detail industry definitions see Professor French's webpage.

${ }^{10}$ Since we do not really know which one is better, we simply use both.
} 
(quintile 1) to highest (quintile 5) every month. The means and standard deviations of the annualized returns of the stocks in the quintiles are presented in Table 8 for both the full sample and the most recent subsample, 2009-2011.

Examining the overall sample means of the stocks sorted by the $R_{t}^{C L}$ loading, we observe that for stocks in the oil industry, the means of annualized returns increase monotonically from the lowest loading quintile to second highest quintile $(11.11 \%, 13.40 \%, 15.02 \%$ and $18.40 \%$ for stocks in quintiles 1 to 4 ). The mean of annualized returns of stocks in quintile $5(18.10 \%)$ is found to be very close to quintile 4 . The results suggest that, after controlling for market risk, stocks with high sensitivities to crude oil price risk have higher average expected returns. In other words, oil price risk is found to be priced into the returns of oil industry stocks. It is also worth noting that the standard deviations of the annualized returns are relatively close throughout the quintiles. The results are very similar when stocks are sorted by the absolute value of $R_{t}^{C L}$. This is because for most stocks in the oil industry, the $R_{t}^{C L}$ loadings are positive (even the negative ones are also very close to zero) and thus, sorting by the absolute $R_{t}^{C L}$ loadings does not change the quintiles much.

The returns sensitivity results are, however, found to be markedly different during the recent sample period. During the period 2009 to 2011, the mean annualized returns are $13.29 \%, 17.14 \%, 21.94 \%, 19.47 \%$ and $16.98 \%$ for quintiles 1 to 5 . They increase from quintiles 1 to 3 then decrease through quintiles 4 and 5 . Sorting the stocks by absolute loading do not change the overall results. We find that for the most recent subperiod, stocks with medium sensitivities to oil price risk have the highest average annualized returns, a result that may be attributed to significant downside risk during the financial crisis. It is possible that the heightened sensitivity of the stock to oil price risk may be an artifact of distressed outliers, which is consistent with lower returns found for distressed stocks in the equity market (Campbell et al. 2008).

The results for the transportation industry provide an interesting contrast. For the 
overall sample, when the stocks are sorted by $R_{t}^{C L}$ loadings, the means of the stocks in quintile 1 and quintile 5 are smaller than the ones in the other three quintiles. However, when the stocks are sorted by absolute $R_{t}^{C L}$ loadings, the means of stocks in quintile 4 and quintile 5 are significantly smaller than the ones in the first three quintiles. Although sensitivities are defined by the values of the factor loadings in Ang et al. (2006), we believe that sensitivities can also be defined by the absolute values of factor loadings. For example, we would argue that a stock with $R_{t}^{C L}$ loading of positive one and another stock with $R_{t}^{C L}$ loading of negative one are actually equally sensitive to $R_{t}^{C L}$ although in the opposite direction. Based on this definition, we conclude that for stocks in the transportation industry the higher the sensitivities to oil price risk the lower the returns. The results in the recent sample period are qualitatively similar.

In the next step, the results are interpreted based on sorting stocks by $\Delta \sigma_{t}^{M F}$ loadings. Compared to the extreme quintiles, we find the means of annualized returns of oil industry stocks in quintiles 2 to 4 are relatively high and close to each other $(18.31 \%, 19.90 \%$, and $17.53 \%$ ). When the stocks are sorted by absolute values of $\Delta \sigma_{t}^{M F}$ loadings, results show that stocks with the highest absolute $\Delta \sigma_{t}^{M F}$ loadings have the lowest mean annualized returns compared to the others. The mean of stocks in quintile 3 is the largest $(21.24 \%)$ and the means of stocks in quintiles 1,2 and 4 are very close to each other. The results of $\Delta \sigma_{t}^{B L}$ loading are very similar to the results of $\Delta \sigma_{t}^{M F}$ loadings. In this analysis, stocks with the highest sensitivities to oil volatility have the lowest mean and highest standard deviation and in this respect the results for the transportation industry are similar to the oil industry.

In summary, results indicate that stocks in different industries are impacted differently by sensitivities to oil price risk. Even though the oil and transportation industries are both closely related to oil price risk, they seem to be affected by different economic mechanisms. The oil price is positively correlated with the oil industry's revenue hence for oil stocks, the higher the sensitivities to oil return (price) risk, the higher the returns. In 
contrast, for transportation stocks, oil price is positively related to their cost or negatively related to their revenue, hence the higher the sensitivities to oil return (price), lower their returns. Additionally, for both oil and transportation stocks, very high sensitivities to oil volatility leads to low returns, which is consistent with the findings in Ang et al. (2006) for the general equity market using the VIX index as a proxy of aggregate market volatility.

\section{Conclusions}

This article examines the relationship between crude oil returns and risk-neutral implied volatility and higher moments, and draws important inferences relating to the commodity's stock versus flow characteristics. We extract the Black-Scholes implied volatility and the model-free implied moments from daily options on the nearby WTI crude oil contract between 2006 and 2011, and then conduct several tests on the association between crude (futures and spot) returns and implied volatility and its innovations. We also extend the investigation to study the pricing of crude oil and oil market volatility risk in the cross-section of oil and transportation stock returns.

We have three primary findings in the paper. (i) The relationship between returns and implied volatility or its innovations is absent for the majority of the subsamples, including those that witnessed large inflows into commodities by the investment public. Each of these results hold when employing either futures or spot prices in the computation of returns. We find crude returns to be more strongly associated with changes to implied volatility (than to implied volatility levels), and also document improvements in the relationship when controls for implied skewness and implied kurtosis are imposed. (ii) Our analysis indicates that the association between returns and changes to implied volatility is only statistically noteworthy over the period spanning the recent financial 
crisis and beyond, 2008-2011. (iii) Finally, we document that oil price risk is priced into the returns of stocks in the oil and transportation sectors.

The evidence from this study should be of interest to those who argue for- or against the case that crude oil prices are impacted by speculative actions. If the data had unambiguously supported a strong relationship between returns and implied volatility (innovations), we could have made the case that crude oil markets "price" the expected variability in crude returns. Such a commodity, that prices distant expectations, will innately qualify as a stock-flow commodity, one whose price may be influenced by speculative actions, primarily stock-building activities. This simple empirical strategy of deploying returns-implied volatility association (for the stock-versus-flow characterization of commodities) is appealing for at least two reasons. First, it is intuitive and fairly easy to implement, and requires only that the commodity has options traded on them (in this regard, options on commodity futures are becoming increasingly ubiquitous). Second, it does not require the implementation of a structural model that might involve modeling demand, an unobservable variable, especially for an asset with both, flow and stock characteristics.

Finally, given that model-free implied volatility and the Black-Scholes implied volatility measures provide upward biased forecasts of realized volatility it may be useful to test the robustness of the results reported in this paper by employing realized volatility estimates of crude oil (see, for example, Wang, Wu and Yang 2008). This is left for future research. 


\section{References}

[1] Adrian, T., J. Rosenberg, 2008. Stock Returns and Volatility: Pricing the Short-Run and Long-Run Components of Market Risk. Journal of Finance, 63(6), 2997-3030.

[2] Adrangi, B., A. Chatrath, R. A. Christie-David, H. Miao, and S. Ramchander, 2014. Stock-Versus-Flow Distinctions, Information, and the Role of Inventory. Journal of Futures Markets. doi: 10.1002/fut.21686.

[3] Alsarhan, A. A., A. A. Khalifa, and O. Al-Titi, 2013. Oil Price Volatility and the Dynamic Systematic Risk in Kuwait's Equity Sector Portfolio using the Kalman Filter Approach. American Journal of Finance and Accounting, 3(1), 24-40.

[4] Ang, A., R.J. Hodrick, Y. Xing, and X. Zhang, 2006. The Cross-Section of Volatility and Expected Returns, Journal of Finance, 51, 259-299.

[5] Baker, S.D., 2012. The Financialization of Storable Commodities. Technical report, Carnegie Mellon University.

[6] Baker, S.D., and B.R. Routledge, 2012. The Price of Oil Risk. Technical report, Carnegie Mellon University.

[7] Bakshi, G., N. Kapadia, and D. Madan, 2003. Stock Return Characteristics, Skew Laws, and Differential Pricing of Individual Equity Options, Review of Financial Studies, 16, 101-143.

[8] Bakshi, G., C. Cao, and Z. Chen, 2000. Do Call Prices and the Underlying Stock Always Move In The Same Direction? Review of Financial Studies, 13, 549-584.

[9] Barsky, R.B., and L. Kilian, 2004. Oil and the Macroeconomy Since the 1970s, Journal of Economic Perspectives, 4, 115-134.

[10] Baumol, W.J., 1962. Stocks, Flows and Monetary Theory, Quarterly Journal of Economics, 76, 46-56.

[11] Buraschi, A., and J. Jackwerth, 2001. The Price of a Smile: Hedging and Spanning in Option Markets. Review of Financial Studies, 14, 495-527.

[12] Buyuksahin, B., M. Haigh, J. Harris, J. Overdahl, and M. Robe, 2011. Fundamentals, Trader Activity and Derivative Pricing. Technical report, American University.

[13] Britten-Jones, M., and A. Neuberger, 2000. Option Prices, Implied Price Processes, and Stochastic Volatility. Journal of Finance, 55, 839-866.

[14] Campbell, J.Y., and L. Hentschel. 1992. No News Is Good News: An Asymmetric Model of Changing Volatility in Stock Returns. Journal of Financial Economics, 31: 281-318.

[15] Campbell, J.Y., J. Hilscher, and J. Szilagyi, 2008. In Search of Distress Risk. Journal of Finance, 63(6), 2899-2939. 
[16] Chatrath, A., H., Miao and S. Ramchander, 2012. Does the Price of Crude Oil Respond to Macroeconomic News? Journal of Futures Markets, 32, 536-559.

[17] Chatrath, A., H. Miao, and S. Ramchander, 2014. Crude Oil Moments and PNG Stock Returns. Energy Economics, 44, 222-235

[18] Chatrath, A., H. Miao, S. Ramchander, and T. Wang, 2015. The Forecasting Efficacy of Risk-Neutral Moments for Crude Oil Volatility. Journal of Forecasting, 34(3), 177190.

[19] Chiang, I., H. Ethan, W. K. Hughen, J. S. Sagi. 2015. Estimating Oil Risk Factors Using Information from Equity and Derivatives Markets. The Journal of Finance, $70(2), 769-804$.

[20] Clower, R.W., and D.W. Bushaw, 1954. Price Determination in a Stock-flow Economy, Econometrica, 22, 328-343.

[21] Coval, J., and T. Shumway, 2001. Expected Option Returns, Journal of Finance 56, 983-1009.

[22] Day, T.E., and C.M. Lewis, 1992. Stock Market Volatility and the Information Content of Stock Index Options, Journal of Econometrics, 52, 267-287.

[23] Deaton, A., and G. Laroque, 1992. On the Behaviour of Commodity Prices, Review of Economic Studies, 59, 1-23.

[24] Ghysels, E., P. Santa-Clara, and R. Valkanov. 2005. There is a Risk-return Trade-off After All. Journal of Financial Economics, 76(3): 509-548.

[25] Guo, H., Z. Wang, and J. Yang. 2013. Time-Varying Risk-Return Trade-off in the Stock Market. Journal of Money, Credit and Banking, 45(4), 623-650.

[26] Gogineni, S., 2010. Oil and the Stock Market: An Industry Level Analysis. Financial Review, 45(4),

[27] Gorton, G.B., F. Hayashi, and K. G. Rouwenhorst, 2013. The Fundamentals of Commodity Futures Returns. Review of Finance, 17(1): 35-105.

[28] Hamilton, J. D., 1996. This is What Happened to the Oil Price-macroeconomy Relationship. Journal of Monetary Economics, 38(2), 215-220.

[29] Hamilton, J.D., and J. Wu, 2013. Risk Premia in Crude Oil Futures Prices. No. w19056. National Bureau of Economic Research.

[30] Hong, H., and M. Yogo, 2012. What Does Futures Market Interest Tell Us About the Macroeconomy and Asset Prices? Journal of Financial Economics, 105(3): 473-490.

[31] Irwin, S., and D. Sanders, 2011. Index Funds, Financialization, and Commodity Futures Markets. Applied Economic Perspectives and Policy, 33(1):1-31. 
[32] Jiang, G.J., and Y.S. Tian, 2005. Model Free Implied Volatility and Its Information Contents, Review of Financial Studies, 18: 1305-1342.

[33] Khalifa, A., H. Miao and S. Ramchander, 2011. Measuring and Forecasting Volatility in the Metal Futures Markets, Journal of Futures Markets, 31, No. 1, 55-80.

[34] Kilian, L., 2008a. Comparison of the Effects of Exogenous Oil Supply Shocks on Output and Inflation in the G7 Countries, Journal of the European Economic Association, 6, 78-121.

[35] Kilian, L., 2008b. Exogenous Oil Supply Shocks: How Big Are They and How Much Do They Matter for the U.S. Economy? Review of Economics and Statistics, 90, 216-240.

[36] Kilian, L., and L.T. Lewis, 2011. Does the Fed Respond to Oil Price Shocks? The Economic Journal, 121, 1047-1072.

[37] Kilian, L., and D.P. Murphy, 2014. The Role of Inventories and Speculative Trading in the Global Market for Crude Oil. Journal of Applied Econometrics, 29(3): 454478.

[38] Kilian, L., and C. Vega, 2011. Do Energy Prices Respond to U.S. Macroeconomic News? A Test of The Hypothesis of Predetermined Energy Prices. Review of Economics and Statistics, 93, 660-671.

[39] Kogan, L., D. Livdan, and A. Yaron, 2009. Oil Futures Prices in a Production Economy with Investment Constraints. Journal of Finance, 64(3):1345-1375.

[40] Kroner, K.F., K. P. Kneafsey, and S. Claessens, 1995. Forecasting Volatility in Commodity Markets, Journal of Forecasting, 14(2), 77-95.

[41] Masters, M.W., 2008. Testimony before the U.S. Senate Committee on Homeland Security and Governmental Affairs.

[42] Martens, M., and J. Zein, 2004. Predicting Financial Volatility: High-frequency Time-series Forecasts vis-à-vis Implied Volatility. Journal of Futures Markets, 21(11), 1005-1028.

[43] Newey, W.K., and K.D., West, 1987. A Simple, Positive Semi-definite, Heteroskedasticity and Autocorrelation Consistent Covariance Matrix, Econometrica 55, 703-08.

[44] Pindyck, R., and J. Rotemberg, 1984. Energy Shocks and the Macroeconomy, Natural Resources Journal 24, 277-296.

[45] Poon, S., and C.W.J. Granger, 2003. Forecasting Volatility in Financial Markets: A Review, Journal of Economic Literature, 41(2), 478-539.

[46] Ready, R. C., 2013. Oil Prices and the Stock Market, Working paper. 
[47] Singleton, K.J., 2013. Investor Flows and the 2008 Boom/Bust in Oil Prices, Management Science, 60(2), 300-318.

[48] Szakmary, A., E. Ors, J.K. Kim, and W.N. Davidson III, 2003. The Predictive Power of Implied Volatility: Evidence from 35 Futures Markets, Journal of Banking and Finance, 27, 2151-2175.

[49] Tang, K., and W. Xiong, 2010. Index Investing and the Financialization of Commodities. No. w16385. National Bureau of Economic Research.

[50] Wang, T., J. Wu, and J. Yang. 2008. Realized Volatility and Correlation in Energy Futures Markets. Journal of Futures Markets, 28(10), 993-1011. 


\section{Table 1: Summary Statistics of Variables}

This table reports summary statistics of all the variables involved in this study for different subsamples.

\begin{tabular}{|c|c|c|c|c|c|c|c|}
\hline Variable & $\mathrm{N}$ & Mean & Std Dev & Skewness & Kurtosis & Minimum & Maximum \\
\hline \multicolumn{8}{|c|}{ Panel A: Daily Full Sample } \\
\hline$R^{C L}$ & 4018 & 0.000 & 0.024 & -0.230 & 2.746 & -0.165 & 0.133 \\
\hline$\sigma^{M F}$ & 4018 & 0.378 & 0.113 & 2.329 & 7.426 & 0.185 & 1.006 \\
\hline$\sigma^{B L}$ & 4018 & 0.369 & 0.107 & 2.334 & 7.556 & 0.185 & 0.999 \\
\hline$\sigma^{H R E}$ & 3995 & 0.353 & 0.126 & 2.167 & 6.097 & 0.127 & 0.994 \\
\hline$\sigma^{H}$ & 3995 & 0.353 & 0.128 & 2.158 & 6.152 & 0.132 & 1.045 \\
\hline$\sigma^{R E}$ & 4018 & 0.352 & 0.127 & 2.170 & 6.247 & 0.029 & 0.997 \\
\hline$\sigma^{L R E}$ & 4004 & 0.280 & 0.108 & 1.881 & 5.997 & 0.000 & 1.012 \\
\hline \multicolumn{8}{|c|}{ Panel B: Daily 2009-2011 } \\
\hline$R^{C L}$ & 755 & 0.001 & 0.024 & -0.229 & 3.042 & -0.131 & 0.105 \\
\hline$\sigma^{M F}$ & 755 & 0.415 & 0.145 & 1.664 & 2.521 & 0.231 & 0.952 \\
\hline$\sigma^{B L}$ & 755 & 0.395 & 0.138 & 1.740 & 2.717 & 0.225 & 0.913 \\
\hline$\sigma^{H R E}$ & 755 & 0.370 & 0.167 & 1.916 & 3.474 & 0.127 & 0.994 \\
\hline$\sigma^{H}$ & 755 & 0.371 & 0.173 & 2.026 & 3.969 & 0.132 & 1.045 \\
\hline$\sigma^{R E}$ & 755 & 0.350 & 0.143 & 1.820 & 4.120 & 0.029 & 0.968 \\
\hline$\sigma^{L R E}$ & 755 & 0.262 & 0.132 & 2.063 & 5.611 & 0.032 & 1.008 \\
\hline \multicolumn{8}{|c|}{ Panel C: Monthly Nonovarlap Full Sample } \\
\hline$R^{C L, M}$ & 189 & 0.011 & 0.102 & -0.905 & 3.378 & -0.500 & 0.263 \\
\hline$\sigma^{M F}$ & 189 & 0.376 & 0.115 & 2.322 & 7.431 & 0.228 & 0.974 \\
\hline$\sigma^{B L}$ & 189 & 0.366 & 0.109 & 2.318 & 7.454 & 0.228 & 0.942 \\
\hline$\sigma^{H R E}$ & 188 & 0.355 & 0.129 & 2.143 & 6.263 & 0.135 & 0.965 \\
\hline$\sigma^{H}$ & 188 & 0.354 & 0.131 & 2.182 & 6.454 & 0.136 & 0.985 \\
\hline$\sigma^{R E}$ & 189 & 0.351 & 0.126 & 1.849 & 4.784 & 0.030 & 0.886 \\
\hline$\sigma^{L R E}$ & 189 & 0.255 & 0.091 & 1.821 & 5.075 & 0.079 & 0.673 \\
\hline \multicolumn{8}{|c|}{ Panel D: Monthly Nonovarlap 2009-2011 } \\
\hline$R^{C L, M}$ & 36 & 0.026 & 0.091 & 0.278 & 0.223 & -0.132 & 0.263 \\
\hline$\sigma^{M F}$ & 36 & 0.409 & 0.146 & 1.754 & 3.180 & 0.249 & 0.884 \\
\hline$\sigma^{B L}$ & 36 & 0.388 & 0.139 & 1.842 & 3.416 & 0.242 & 0.846 \\
\hline$\sigma^{H R E}$ & 36 & 0.366 & 0.167 & 1.842 & 3.574 & 0.175 & 0.889 \\
\hline$\sigma^{H}$ & 36 & 0.365 & 0.170 & 1.929 & 3.947 & 0.173 & 0.933 \\
\hline$\sigma^{R E}$ & 36 & 0.344 & 0.147 & 1.307 & 3.239 & 0.030 & 0.837 \\
\hline$\sigma^{L R E}$ & 36 & 0.246 & 0.101 & 1.318 & 2.623 & 0.079 & 0.562 \\
\hline
\end{tabular}




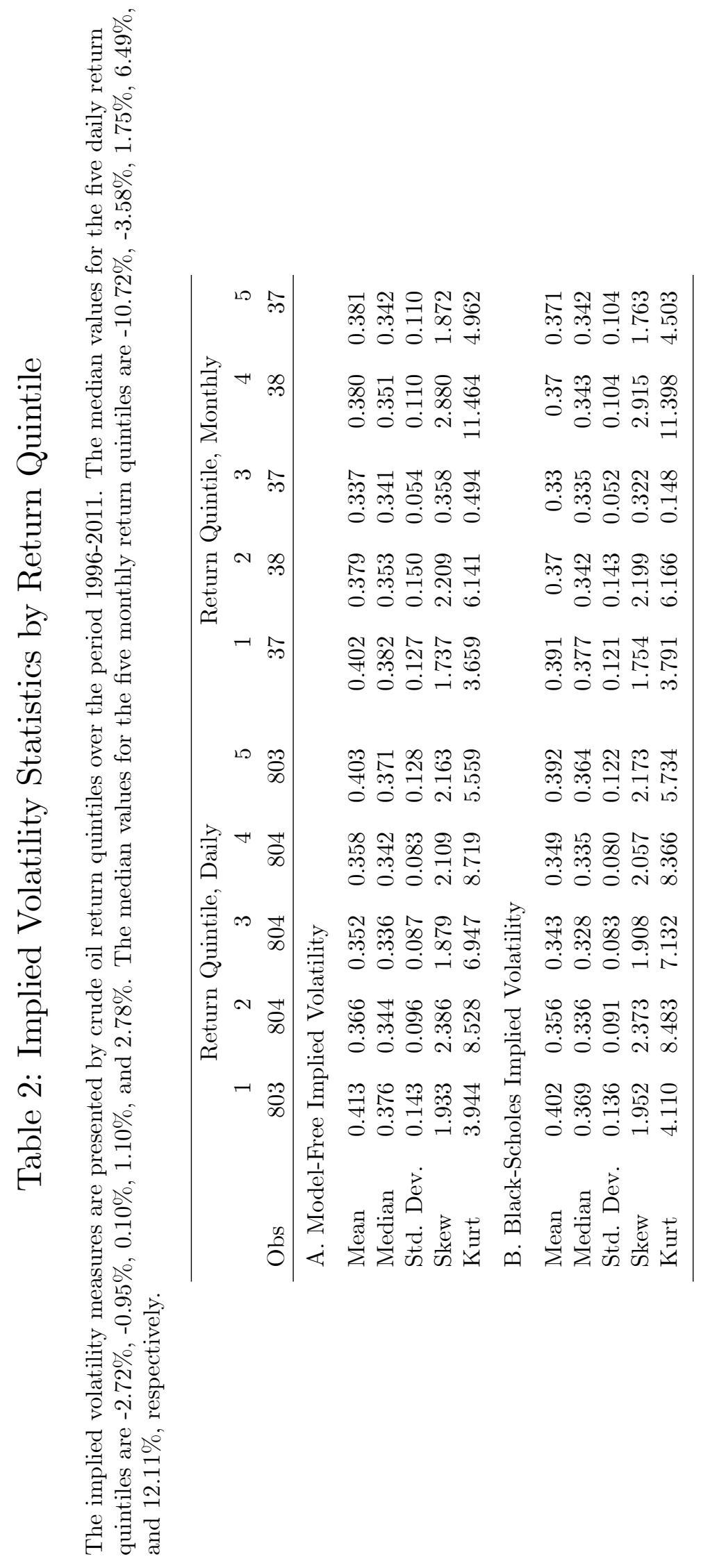




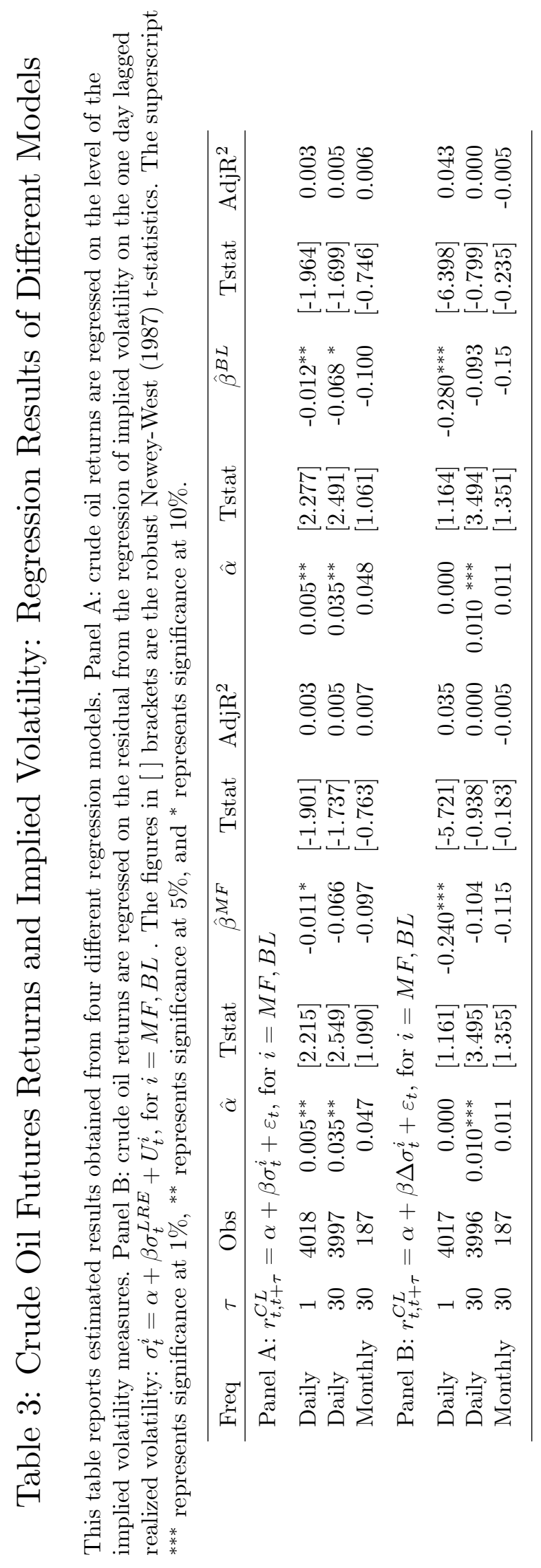




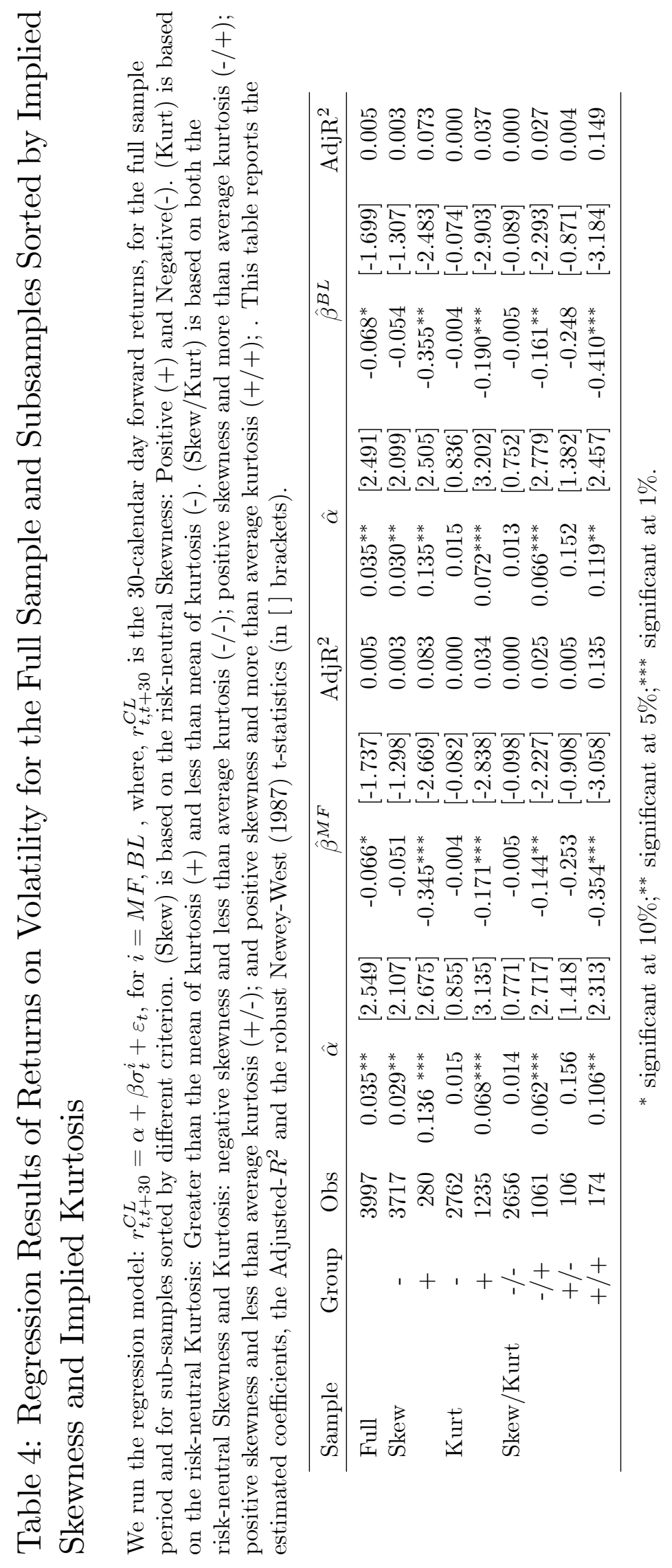




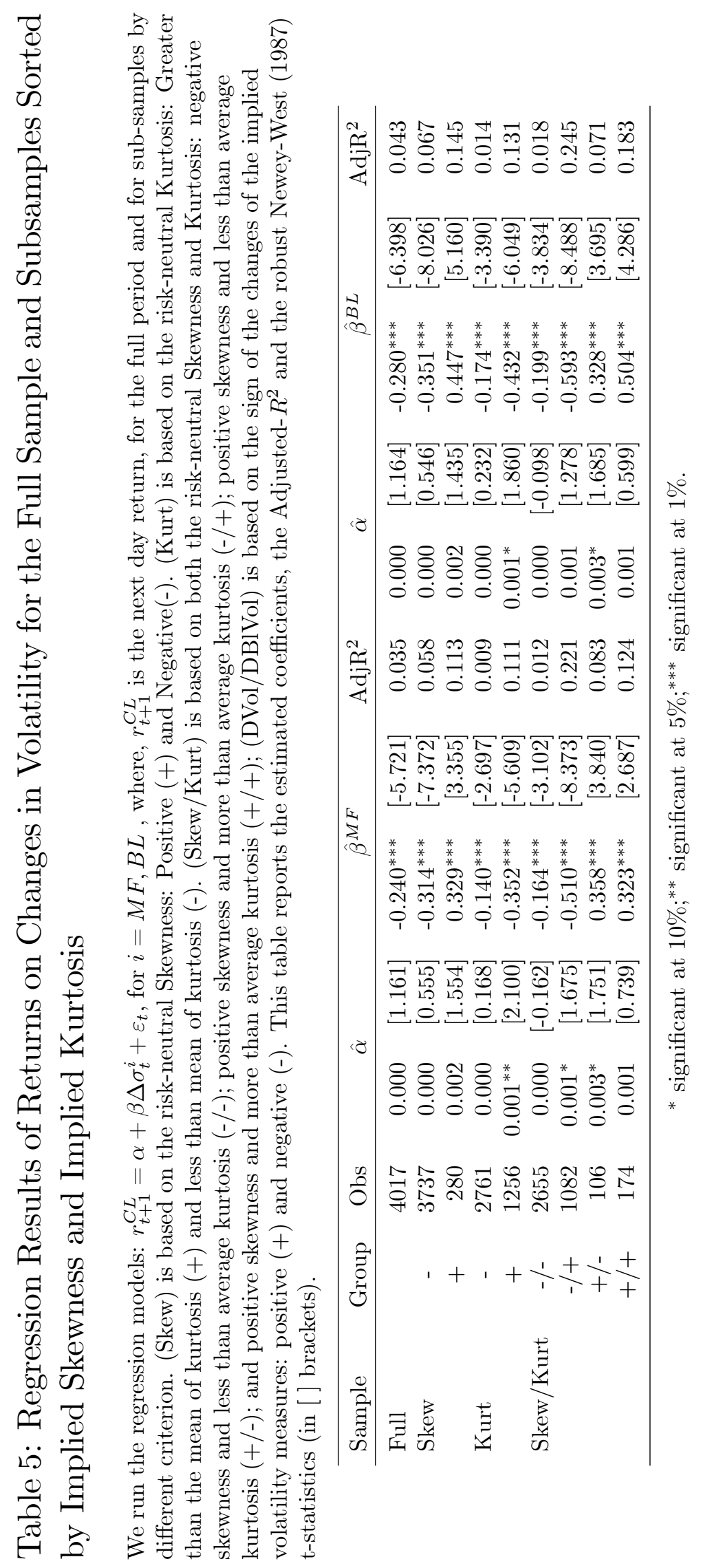




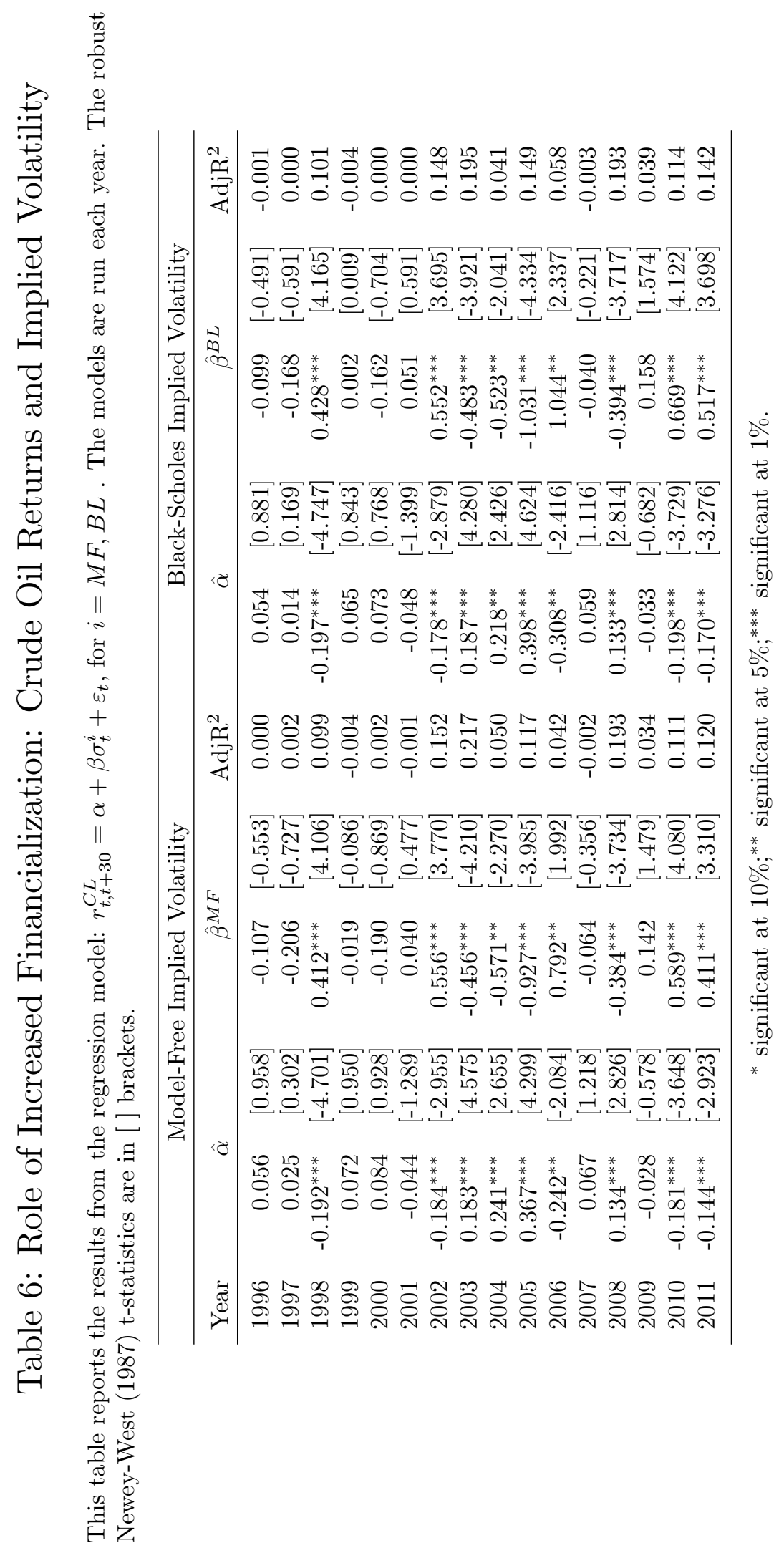




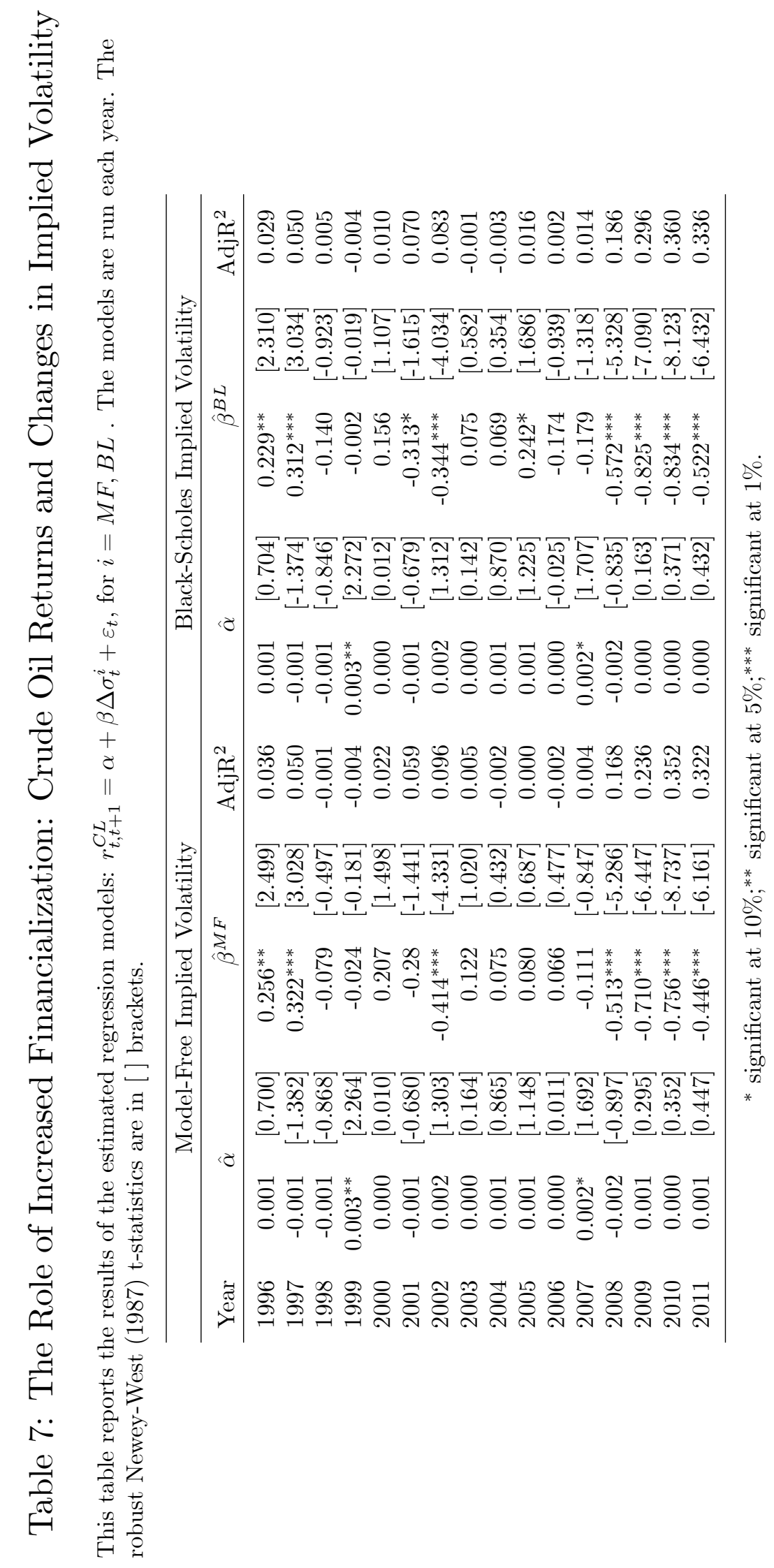




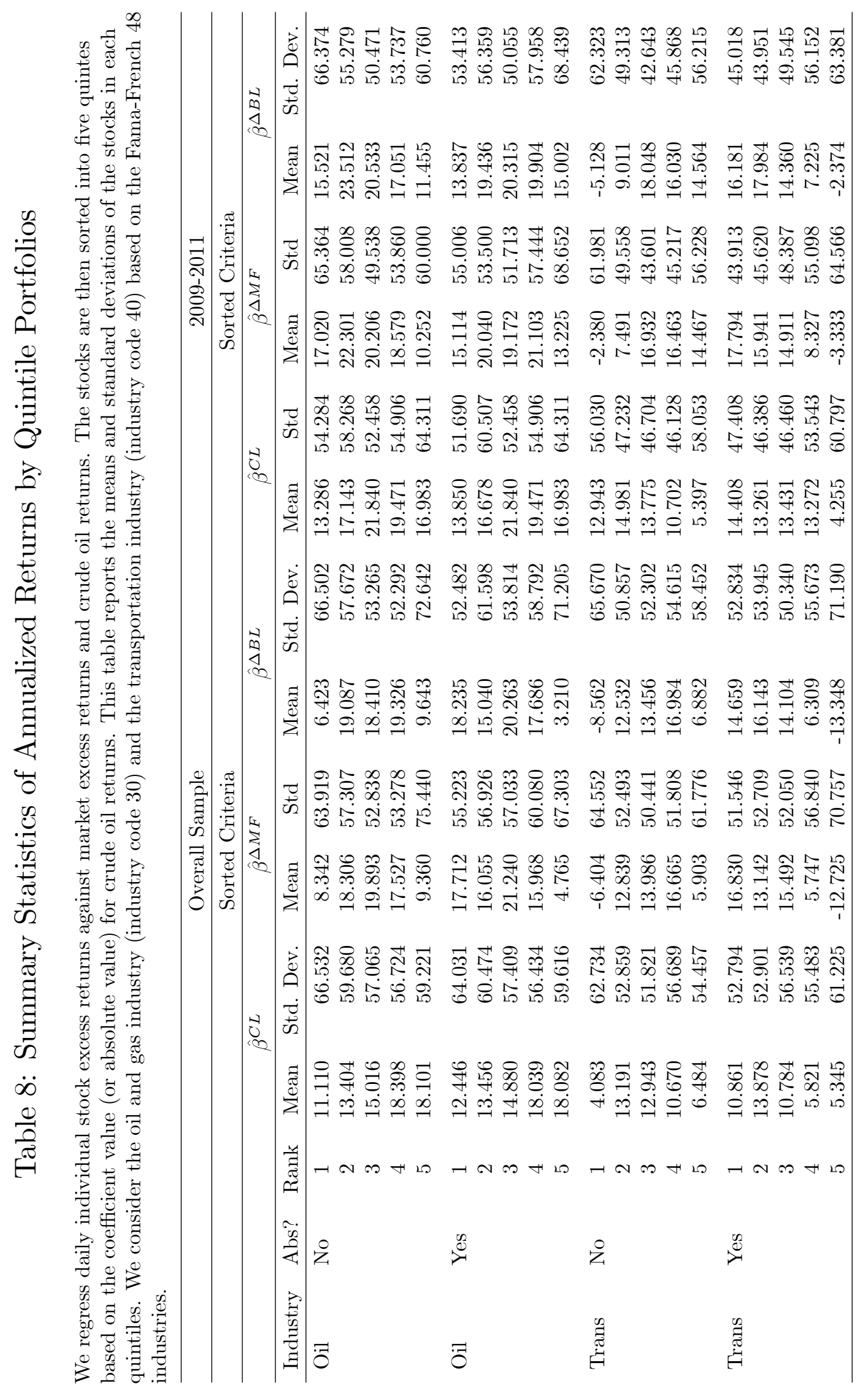

